\title{
Complex additives for concretes on the base of caprolactam
}

\author{
Yulia Sokolova ${ }^{1}$, Marina Akulova ${ }^{2}$, Vyacheslav Polyakov ${ }^{3}$, Alla Sokolova ${ }^{1}$, and Igor \\ Polyakov $^{4}$ \\ ${ }^{1}$ Moscow State University of Civil Engineering, Yaroslavskoe shosse, 26, Moscow, 129337, Russia \\ ${ }^{2}$ Ivanovo State Polytechnic University, 153000, Sheremetyevsky prospect, 21, Ivanovo, Russia \\ ${ }^{3}$ Plc "Ivchimprom:, 153021, Kuznetsova street, 116, Ivanovo, Russia \\ ${ }^{4}$ Mechanical Engineering Research Institute of the Russian Academy of Sciences, 101990, Maly \\ Kharitonyevsky pereulok,4, Moscow, Russia
}

\begin{abstract}
In the modern construction operations, complex multifunctional additives are the most in demand. Application and development of chemical additives enable to consider the modern concrete as a complex composite material, with the properties surpassed the combinations of the properties of its components. In the paper, the action mechanisms of various types of plasticizers and superplasticizers are studied as well as their impact on the properties of concrete mixture and concrete. The most popular plasticizers of concrete mixtures are superplasticizer C-3, alkaline waste of caprolactam process, and technical lignosulphonates. The products of oligomerization of $\varepsilon$-caprolactam in the organic substance medium or its interaction with various sustances of synthetic or natural origin are considered perspective multifunctional additives of building mixes. In the paper, the properties of additives obtained by the method of mechanochemical activation of the mixture containing oligomers of $\varepsilon$-caprolactam, superplasticizer C-3, technical lignosulphonate, and inorganic salts are researched. The carried out investigation has demonstrated improved plasticizing and water retention properties of the additives as well as acceleration of concrete stress generation at the early strength stage. Based on the research findings for the obtained complex additives for the concrete B40, it was stated that the additives obtained by mechanochemical activation of the initial mixture perform as effective plasticizers and concrete hardeners.
\end{abstract}

\section{Introduction}

Increasingly stringent requirements for modern construction operations precondition the necessity to expand the range of applied chemical additives for concrete, retaining its positions as the main building material. Along with that, research and development provision of all technological cycle of concrete production, including the level of machinery and technology of cement manufacturing, are the determinants. This stipulates the increased requirements to chemical additives for concrete, which are universal instruments for modifying physical and chemical properties of concrete.

The most popular plasticizers of concrete mixtures are alkaline waste of caprolactam process, modified alkaline waster, technical lignosulphates, and sulphate-cellulose liquor. 
However, their application as monoadditives in concrete production technology is less effective than of superplasticizers and multi-component modifiers of complex action $[1,13]$.

The company «Suddentsche Kalstickstoff - Weyke» first launched manufacturing of superplasticizers as saleable products. In the USSR, mass production of superplasticizers started in 1978 when the first production line of superplasticizers on the base of condensation products of naphthalene sulphonic acids and formaldehyde [2] was installed.

Superplasticizer C-3 and its modifications on the base of sulphonated naphthalene formaldehyde compounds has gained popularity in construction practice. The given product is related to the category of anionic surfactants. It represents the mixture of oligomers and polymers, being the substance component base containing unreacted salt - $\beta$ - naphthalene sulfonic acid ( $\beta$ - salt) and sodium sulphate [3]. Physical and chemical properties of the superplasticizer C-3 are closely linked to its characteristic features, first of all, to its ability to absorb on the various phase boundaries and to form spatial coagulated structures in both the cement system volume and in the surface layers [4].

It is known that the mechanism of superplasticizer's performance is conditioned by its adsorption capacity $[4,5,6]$. Superplasticizer's molecules are absorbed on the surface of cement particles and colloid and colloid-crystalline structures formed during hydration and form the finest mono- or bimolecular layer. This leads to the lowering of interfacial energy and facilitates disaggregation of non-hydrated and hydrated cement particles. Along with that, immobilized water, acting as a plasticizing lubricant, is released. The formed adsorption layer smoothers particles micro roughness down, thus reducing frictional coefficient between them. The homonym electrical charge, appeared as the result of superplasticizer's adsorption on the surface of solid phase particles, eliminates the possibility of their coalescence due to electrostatic forces and reduces viscosity of cement slurry mix. The stage following the cement hydration is the growth of crystalline newgrowths. This leads to the loss of concrete slurry workability [6,7].

The amount of tricalcium aluminate and mineral additives containing in the clinker has a significant impact on the adsorption capacity. When its content in the clinker exceeds $7 \%$, adsorption capacity of cement particles in relation to superplasticizer is increasing significantly [2].

Cement acts in a similar way when its composition includes mineral additives containing active silica oxide. Weighing-out required to obtain concrete slurry with high workability, when the slump of concrete cone exceeding $20 \mathrm{~cm}$, varies significantly in the range of $0.3-0.4 \%$ for low- and semi-alumina clinker cements; up to $0.8-1 \%$ for high alumina cements more than $7 \%$. Plasticizing ability of superplasticizers increases when the optimal fineness of grinding is reached. This is achieved by the selection of the most effective intensifiers of cement clinker grinding. Moreover, composition and quality of aggregates in the concrete slurry influence the effectiveness of superplasticizers. For example, partial replacement of crushed granite stone for crushed limestone enhances workability of concrete slurry when the amount of added superplasticizer remains stable [8].

In the modern construction operations, complex multifunction additives are in great demand. This becomes extremely important at ever-increasing rate of erection of in-situ and prefabricated structures.

Application and effectiveness of complex additives of different purpose on the base of naphthalene-formaldehyde compounds is preconditioned by the objective to make the full use of the positive properties of the particular additives, mostly, surfactants and hardeners applied in various combinations. The principal advantages of complex additives in comparison with the discrete ones are: 
1. Multi-purpose action, i.e. the ability to lead to several effects (for example, to increase concrete slurry workability and accelerate hardening);

2. The ability to smooth undesirable effects of the particular additives included in the composition (for example, neutralizing the inhibiting impact of the surfactant on cement hydration by means of simultaneous introduction of a hardener, etc.);

3. The ability to level out the overall impact of additives on cements with various compositions;

4. To prevent or reduce destructive processes and accelerate concrete hardening at thermal treatment [9].

Complex additives on the base of superplasticizers have a multiple effect on construction and technical properties of concrete that include the prominent increase in impermeability and frost resistance of concretes. Superplasticizer Relamix SP-1, the industrial mixture of sodium rhodanide and thiosulphate and sodium polynaphthalene methylene sulphonate, containing the certain amount of admixture of sodium sulphate and resinous substances, could be seen as the example of the practical use of the complex additive. This additive is attributed to the group of plasticizing, water-reducing, and hardening admixtures [9].

The authors [8,9] have pointed out that the findings of the tests implemented by the US company «Duke Eng. Services» had related the additive "Relaxol" to the category "F". This additive significantly reduces the amount of mixing water and can be regarded as a superplasticizer exhibiting accelerating effect.

There is also known the superplasticizer "Relaxol", used successfully in Russia, Ukraine, Belarus, Kazakhstan, and Poland. The introduction of "Relaxol" during the grinding of cement clinker at cement plants leads to the rise of pebble mill productiveness. At the same time, there observed the growth of specific surface area and enhancement of physical and chemical properties of Portland cement and Portland blast-furnace cement. In addition, application of these cements ensures the lowering of water requirement and accelerated rate of early strength development of concrete $[6,9]$.

Thus, the applied and developed chemical admixtures enable to consider modern concrete as a complex composite material, with its properties surpassing the combination of properties of its components.

The products of oligomerization of $\varepsilon$-caprolactam in the organic substances medium or the products of its interaction with various substances of synthetic and natural origin are considered perspective multifunctional additives for building mixes [8,14,15].

In the composition of complex additives, there included chemical substances designated for accelerating the hardening process of concrete slurry. This factor is regarded as one of the crucial ones for manufacturing concrete articles or for concrete casting at the construction sites. Such substances include granulated calcium chloride $\left(\mathrm{CaCl}_{2}\right)$, also known as UniPell ${ }^{\mathrm{TM}}$. It is massively used in the production of aerated concrete, polystyrene concrete, concrete, masonry blocks, and flagstones [10].

Application of calcium chloride allows reducing cement consumption by $5-10 \%$, cutting the time of concrete mold clearance by the factor of 2.0-2.5, increasing the 24-hour concrete strength by the factor of 1.5-2; augmenting ultimate compressive strength by $10 \%$; intensifying hardening process of concrete due to the thermal effect of hydration reactions and exo-effect of dissolution reaction of calcium chloride that is akin to elevating hardening temperature by $15-20^{\circ} \mathrm{C}[8,11]$.

\section{Experimental part}

The purpose of the present research was developing complex multipurpose additives on the base of chemical substances produced on the territory of the Russian Federation. 
When planning and carrying out the experiments, the following advantages of complex additives over the monoadditives have been taken into account:

1) polyfunctional action, i.e. the ability to cause several meaningful effects (to increase workability of concrete mixtures on the stage of transporting and molding, to accelerate the hardening process and to enhance concrete strength during its service life);

2) the ability to neutralize undesirable effects of particular admixtures included into the composition (neutralizing the inhibiting impact of the surfactant on cement hydration by means of simultaneous introduction of a hardener, etc.);

3) the ability to level out the total impact of the additive on cements produced by different manufacturers and distinguished by its composition;

4) to ability to prevent or reduce destructive process during steam curing of concrete [1].

In order to obtain complex additives, the following initial components have been chosen: superplasticizer C-3, calcium chloride, caprolactam, sodium sulphate, and technical lignosulphate. The initial mixtures have been prepared for the additives A-1 and A-2.

The composition of the additive A-1 (\% weight):

superplasticizer C-3

20.0

caprolactam

20.0

calcium chloride

20.0

sodium sulphate

30.0

The composition of the additive A-2 (\% weight):

technical lignosulfonate

caprolactam

20.0

calcium chloride

30.0

sodium sulphate

30.0

In order to obtain experimental additives, there was used the method of mechanochemical interaction (activation) of the initial components [16]. The laboratory vibratory mill was used, the total volume of the feed end $5.0 \mathrm{dm}^{3}, 80 \%$ of the mill was filled with grinding bodies - steel balls ShKh-15- with the diameter ranging from 1 to 15 $\mathrm{mm}$. The maximum effective volume of loaded fine grade materials accounts for $1.5 \mathrm{dm}^{3}$. The driving power of the vibratory mill was 1500 watt. The vibrational frequency of the mill was 25 hertz that provides obtaining fine grade powder. The cycle of mechanochemical activation of the components lasted 120 minutes for each additive, then the material was unloaded via the lower discharge gate of the mill. After that, the grain-size analysis was done with the use of the mesh sieve set (table 1).

Table 1.The grain-size analysis of the additives A-1 and A-2

\begin{tabular}{|c|c|c|c|c|}
\hline \multirow{2}{*}{ Sieve number } & \multicolumn{2}{|c|}{ Additive A-1 } & \multicolumn{2}{c|}{ Additive A-2 } \\
\cline { 2 - 5 } & \multicolumn{2}{|c|}{ sieve residue } & \multicolumn{2}{c|}{ sieve residue } \\
\cline { 2 - 5 } & $\mathrm{g}$ & $\%$ & $\mathrm{~g}$ & $\%$ \\
\hline 0.14 & 5.52 & 1.2 & 12.68 & 2.8 \\
\hline 0.08 & 15.18 & 3.3 & 24.86 & 5.5 \\
\hline 0.071 & 150.88 & 32.8 & 183.96 & 40.7 \\
\hline 0.063 & 94.3 & 20.5 & 79.8 & 17.6 \\
\hline 0.045 & 194.12 & 42.2 & 150.7 & 33.4 \\
\hline Total & 460 & 100 & 452 & 100 \\
\hline
\end{tabular}


It is evident from the table 1 that at the same parameters of vibration effect on the initial mixtures of the additive A-1 and A-2, the obtained powders of the additives differ in their grain size. The additive A-1 has a lesser residue on the sieves N14, 008, 0071. The additive A-2 has a lesser residue on the sieves N 0063, 0045. Such a difference in grain size composition of the additives $\mathrm{A}-1$ and $\mathrm{A}-2$ could be related to the distinguished dispersiveness of the initial superplasticizer C-3 and technical lignosulphonate. However, the most plausible cause of this phenomenon is the different degree of the particles aggregation, being the result of solid-phase interaction of caprolactam and other components. The processes developing in the initial mixtures exposed to vibration loading are of random-probabilistic type, in compliance with the laws of nonlinear wave mechanics.

The obtained additives A-1 and A-2 have been used during concrete mixture hydration in the quantity of $0.3 \%$ from the cement weight. For the tests, heavy-weight concrete of the grade B40 has been used. After forming, the samples-cubes have been placed into steam curing chamber for curing. The tests of concrete samples have been carried out at the hydraulic press, accounting for the coefficient $(\mathrm{K}=0.95)$ that allows for the actual size of the cubic sample edge equal to $100 \mathrm{~mm}$. The tests results for compressive strength of the concrete with additives A-1 and A-2 are shown in the table 2.

Table 2. Strength of concrete samples B-40 with additives

\begin{tabular}{|c|c|c|c|c|c|c|c|}
\hline \multirow{2}{*}{$\mathrm{N}$} & \multirow{2}{*}{ Additive } & \multicolumn{6}{|c|}{ Ultimate compressive strength, } \\
\cline { 3 - 8 } & & 1 day & 3 days & 7 days & $\begin{array}{c}14 \\
\text { days }\end{array}$ & 21 day & $\begin{array}{c}28 \\
\text { days }\end{array}$ \\
\hline 1 & No additives & 18.5 & 20.1 & 26.2 & 32.9 & 36.2 & 41.6 \\
\hline 2 & A-1 & 20.5 & 24.0 & 34.9 & 37.9 & 49.1 & 53.3 \\
\hline 3 & A-2 & 24.0 & 26.2 & 36.0 & 39.2 & 51.3 & 56.4 \\
\hline
\end{tabular}

From the table 2 follows that the additives A-1 and A-2 represent plasticizing additives and hardeners according to their functional properties. In addition, acceleration of strength development increases after 7 days that proves their high effectiveness.

In order to define the impact of the additives A-1 and A-2 on the structure of the hardened cement paste, the method of electron scanning microscopy was used.

The characteristic features of the surfaces of the hardened cement paste of the reference compositions have been studied on the apparatus SEM VEGA 3 TASCAN. The received images of samples surfaces with the resolution $5 \mathrm{mcm}$ are presented in the figure 1.

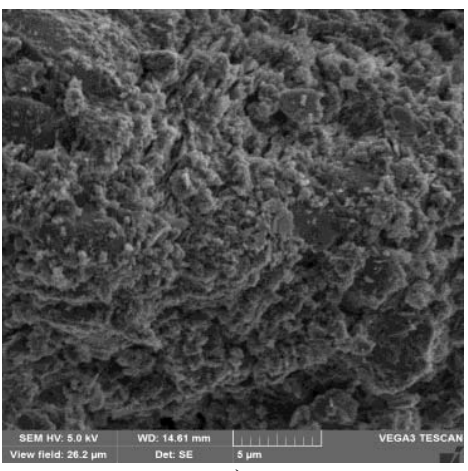

a)

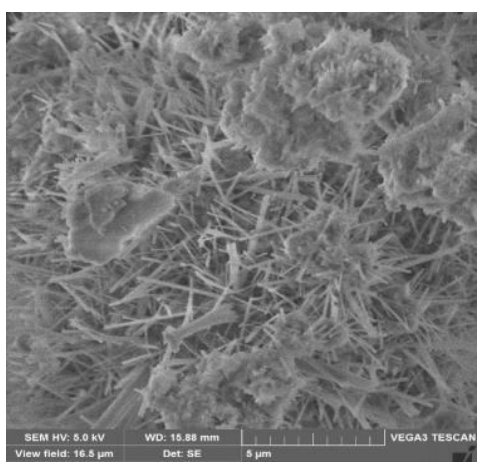

b)

Fig. 1. Cut of the hardened cement paste with additives: a) with the additive A-1; b) with the additive A-2 
The images of the researched samples' surfaces of the hardened cement paste with the additives A-1 and A-2 demonstrate that their impact on formation of the cement paste structure could be different. They also prove random-probabilistic character of occurring chemical and physic-mechanical processes. The image of the hardened cement paste with the additive A-1 gives the evidence of the structure of crystal-fiber aggregates formed at the baseline of the research. In addition, it should be assumed that this structure would eventually change due to continuous yielding of crystals and destruction of coagulated structures.

The image of the hardened cement paste with the additive A-2 shows that the researched surface is more uniformly organized, with minimal inclusion of pronounced crystalline and amorphous-crystalline structures. In general, the images of the researched samples' surfaces confirm that properties' alteration of both additives and the obtained hardened cement paste from the initial compositions of the complex additive when the mechanochemical method of their treatment remains permanent.

The alteration of additives' properties as a function of their initial compositions is also proved by the results of infrared spectroscopy of the samples of hardened cement paste with the additive A-1 (figure 2) and the additive A-2 (figure 3).

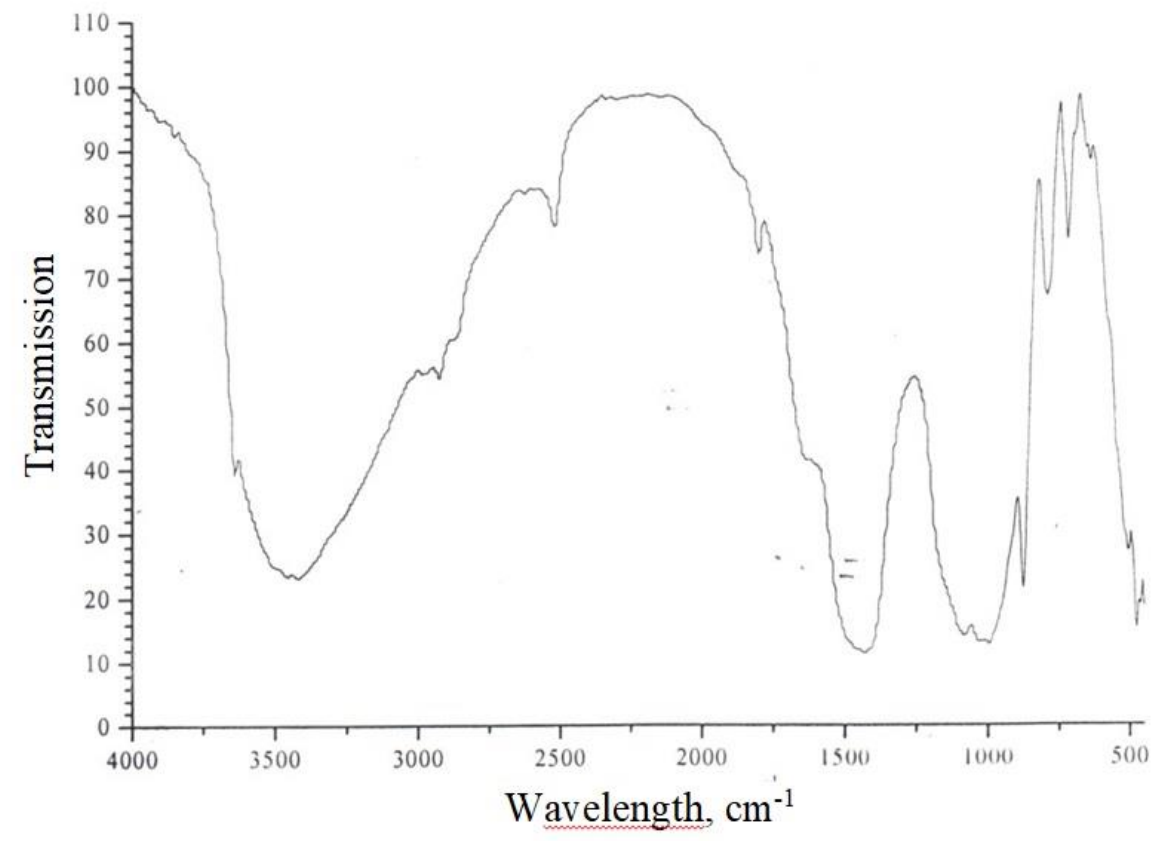

Fig. 2. Infrared spectrum of the hardened cement paste with the additive A-2 


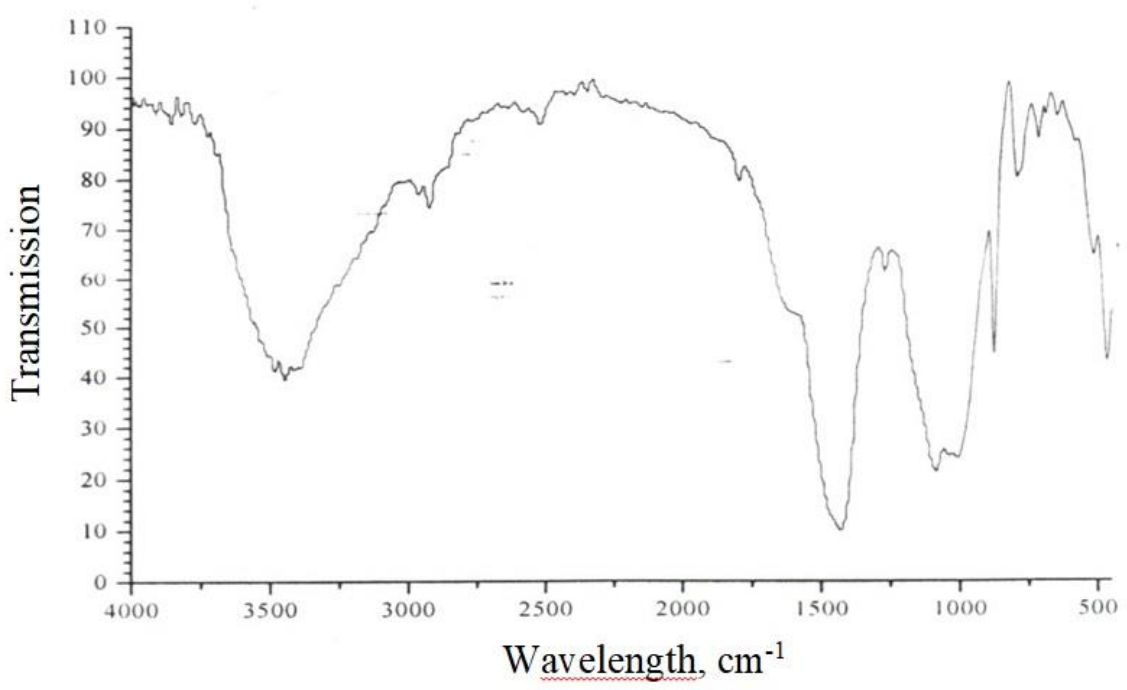

Fig. 3. Infrared spectrum of the hardened cement paste with the additive A-2

As the spectra show, the peaks in the intervals $3000-2500$ and $1500-900 \mathrm{~cm}^{-1}$ are more pronounced for the hardened cement paste with the additive A-2. This phenomenon points at more uniformly organized crystalline structure of the hardened paste of a binder and demonstrates higher strength of concrete at the tests.

\section{Conclusions}

With regards to findings of the study of experimental additives for concrete B40 it was stated that the additives obtained by the method of mechanochemical activation of the initial mixture containing caprolactam, superplasticizer C-3, technical lignosulphonate, sodium sulphate, calcium chloride can perform as effective plasticizers and concrete hardeners.

Vibration action on the particles of the initial components of the additives results in their grinding at first, followed by breakdown of crystalline structures with the rupture of intermolecular and intramolecular chemical bindings that preconditions spike in active radicals in the mixture volume that react intensely with each other. Along with that, crushing action of the grinding bodies is increased multiple time by vibration effect on the solid phase by the frequency 25 Hertz. The forming intermediate compounds decompose again and react with formed products of interaction of mixture components. The admixtures obtained in the result of solid phase synthesis are more reactive than additives "Relamix", "Relaxol" and their analogs, including foreign ones.

\section{References}

1. V. Polyakov, V. Padokhin, M. Akulova, S. Syrbu, Enhancement of strength properties of heavy-weight concretes by chemical additives on the base of oligomers and E-caprolactam, Rus. J. of Chem. and Chem. Techn., 55, 118 (2012)

2. A. Vovk, Modern construction with modern additives, Stroyprofile, 8 (54), 47 (2006) 
3. S. Phedosov, M. Akulova, T. Slizneva, The study of dispersive composition of the nanostructurized liquid used for fine grain concrete hydration, Proceed. of the Sc. Works RAACS, Moscow, 474 (2018)

4. M. Akulova, O. Seliverstova, The influence of complex plasticizing air entraining additive on the properties of hardened cement paste and its strength of various mineralogical composition, Constr. and renov., 2, 55 (2014)

5 A. Sheikin, Yu. Chekhovsky, M. Brusser, Structure and properties of hardened cement paste, Stroiizdat, 344 (1979)

6. P. Zaitsev, Concrete mixtures and concrete with chemical additives on the base of modified lignosulphonates, Cement and its appl., 4, 39 (2004)

7. L. Vinogradova, Influence of introduction of the superplasticizer Polyplast SP-3 on the properties of concrete, Glass and ceramics, 4, 39 (2018)

8. V. Khozin, V. Sal'nikov, N. Morozova, Influence of complex additive on concrete strength development, The modern prob. of mat. science, Voronezh, 506 (1999)

9. V. Alekseev, I. Kharchenko, A. Kharchenko, S. Bazhenova, A. Beterbiev, Modified concrete mixtures for spatial structures applied by the plaster base method, Vestnik MGSU, 11, 48 (2016)

10. A. Kravtsov, S. Tsybakin, T. Evseeva, K. Sobolev, V. Potapov, Poured concrete with by-products of copper-smelting industry and nanosilica, Vestnik MGSU, 12 (9), 1010 (2017)

11. Yu. Bazhenov, V. Voronin, L. Alimov, A. Bakhrakh, O. Larsen, V. Solov'ev, D. V. K. Nguyen, High quality self-compacting concretes with by-products of coal combustion, Vestnik MGSU, 12 (12), 1385 (2017)

12. V. D. K. Nguyen, Yu. Bazhenov, O. Aleksandrova, Influence of quartz powder and mineral additives on the properties of high effective additives, Vestnik MGSU, 14 (1), 102 (2019)

13. M. Akulova, V. Padokhin, V. Polyakov, Influence of complex additives on the base of carpolactam oligomers on physical and mechanical properties of heavy-weight concrete, Proceed. of the round table dedic. Sc. School RAACS, 44 (2013)

14. L. Vinogradova, Yu. Gracheva, Influence of universal additives best on the concrete properties, Proceed. of the Voronezh State University of Eng.Techn, 80 (4), 361 (2018)

15. P. Yukhnevsky, Influence of chemical additives-plasticizers on structure and properties of hydrosilicate gel, News of higher educ. inst. Construction, 4, 43 (2013)

16. B .Isakulov, M. Akulova, B. Kul'sharov, A. Sartova, A. Isakulov, Obtaining and study of the properties of binders on the base of by-products of oil and gas industry, Expert: theory and practice, 5, 34 (2020) 